\title{
The Conceptual Foundations of National Terminological Information System
}

\author{
Rasim M. Alguliyev ${ }^{1}$, Afruz M. Gurbanova ${ }^{2}$ \\ ${ }^{1,2}$ Institute of Information Technology, Azerbaijan National Academy of Sciences 9A, B. Vahabzade street, \\ AZ1141, Baku, Azerbaijan
}

Received: 15 March 2018; Accepted: 08 June 2018; Published: 08 July 2018

\begin{abstract}
The article presents issues of the establishment of National Terminological Information System as one of the development perspectives of national terminology. The current state and problems in terminology sphere in Azerbaijan are explored and the necessity of system establishment is justified. Ongoing research works in computational terminology field within the system are mentioned and several conceptual approaches are presented. International practice and standards in this direction are investigated and analyzed. Conceptual foundations and architecture-technological principles of the National Terminological Information System are developed. Primary functions of web-portal developed within the system framework are presented. As a result of the study on the system establishment, the future prospects of the National Terminological Information System have been identified. The article also stresses the expected outcomes as a result of the implementation of National Terminological Information System.
\end{abstract}

Index Terms: Lexicography, terminology dictionary, computational terminology, terminology database, terminology registry.

(C) 2018 Published by MECS Publisher. Selection and/or peer review under responsibility of the Research Association of Modern Education and Computer Science.

\section{Introduction}

At present, special importance is accrued to terminology problems as a part of a language policy. The state and development prospects of the state language is interlinked with the level of development of terminology, its regulation, systematization, stability and wide range of spheres of application.

As the pursuance of any activity at professional level is related to correct and accurate use of words, dictionaries have played an important role in ongoing information processes since the invention of books.

* Corresponding author.

E-mail address: r.alguliev@gmail.com, afruz1961@gmail.com 
Recently, dictionaries have gained vast importance in the process of collection and transfer of information due to the development of information technologies.

Electronic dictionaries (e-dictionaries) reflect new and specific type of information technologies and enables the acquisition and use of information during the study of various aspects of language. Finally, e-dictionaries present a new method of organizing primary data and new types of work with information.

Broad circle of researchers has been engaged in research of digitalization issues of lexicographic works and terminology science, modelling in linguistics, as well as in lexicography and search is being continued.

Such that, the writings of Drezen et al. [1-4] renowned scholars are devoted to the problems of internationalization of scientific-technical terminology, the study of computer application in linguistics research, the preparation of scientific-technical dictionaries in information provision systems and application issues, principles of term selection, preparation of the glossary of terminology dictionaries, methods of the analysis of terminology lexicon, etc.

The digitalization of all terminology dictionaries is of great importance as the use of those by scientists and experts in any field of activity is facilitated as such.

Terminology information system is a system of storage of all terminology dictionaries interlinked with semantic relations. In other words, terminology information space - is a semantic network based on a set of all terms developed by a human.

In recent years, architecture approach has gained credit as a basis of methodology of the development of complex information systems based on multi-aspect notion on a developed system in general and providing its development.

The research offers an architectural and technological model of the National Terminology Information System (NTIS), which is based on the international standards and expertise, and analyzes the opportunities provided by the system. The goal of the system is to centralize existing and future terminological dictionaries in the Azerbaijani language and to provide their availability for each user, to involve different layers of society, including our compatriots living abroad, to the terminology generating, and to attract to a wide community to the process of new term generation through interactive forums.

\section{Related Work}

Determination of the rules for systematic and dynamic terminology building is of great importance for the solid foundation of the terminology theory. The Tokyo National Institute of Informatics professor Kyo Kaqeuran presents the interaction of the abovementioned two factors in certain areas of the Japanese terminology in his book The Dynamics of Terminology published in 2002 [5]. Here, he thoroughly reviews the relationships between terminology and their constituent elements, and the interconnection of the elements with the types of conceptual combinations used in terminology building. The author presents quantitative analysis of the development patterns of terminology.

Irish scientist, computer science professor Ahmad Khurshid studies neuron calculations, terminology and ontology, NLP, in particular, information extraction and so on. His studies on neuronal calculations have led to multi-net neuron systems imitating the language evolution. This system was used in the joint search for images and their textual description. He explores terminology and ontology, and the practical purpose of his research is to create an information system capable of providing various conditions [6].

An article titled " Towards a New Generation of Terminological Resources: An Experiment in Building a Terminological Knowledge Base (TKB)" representing the results of the fundamental research of its co-author Ingrid Meyer, describes the project of terminological knowledge base building called COGNITERM. The article focuses on modern development in lexicological informatics and knowledge engineering. This work also describes the structure of COGNITERM and presents its advantages compared to the traditional terminology bank. Moreover, the article includes numerous methodological issues [7]. This study focuses on the implementation and development of TKB concept to facilitate the process of knowledge acquisition.

In the 1990s of previous century, Cambridge University (UK) professor Branimir Boguraev (computer 
linguistics) and Stanford University (US) professor Bet Levin attempted to compare lexical knowledge bases (LKB) with lexical data base (LDB). They believe that LKB and LDB differ according to two characteristics. Thus, LDB provides lexical characteristic based on synonym of word, whereas LKB provides summarization and produces a lexical result, and hence expands the lexicon [8]. Both characteristics are of great importance for TKB.

\section{Current State and The Necessity of Establishment of National Terminology Information System}

The development of terminology in Azerbaijan is attributed to 6th-7th centuries. Starting from that period of time, terminology has overcome specific development route and practical steps have been taken towards its activity starting from 20's years of $19^{\text {th }}$ century. That is, Terminology Commission has been established under the Soviet of Popular Commissars in 1922 with the initiative of Narimanov and Aghamalioglu and its activity has continued under the Azerbaijan Central Executive Committee since 1923 [9].

The institution has been active as the Committee of Terminology under the Presidium of Azerbaijan National Academy of Sciences starting from 1952, as Terminology Commission (TC) under Presidium of ANAS since 2000 and continues its activity as TC under the Cabinet of Ministries of the Republic of Azerbaijan.

Throughout these years, various dictionaries have been prepared by scientists and experts of all scientificresearch institutions and higher education institutions of the Republic. Dictionaries enable people speaking different languages to communicate. Dictionary is also a tool for learning native and foreign languages, helping to expand and strengthen knowledge. Modern terminological dictionaries play a particular role in rapid development of science and technology. Recently, the number of terminological dictionaries has sharply increased and led to an increase in the number of other forms of dictionaries.

Note that the number of terminological dictionaries in Azerbaijan in 1920-1952 was ten times more than other forms of dictionaries. Since the 50s of previous century up to 300 bilinguals, multilingual and explanatory dictionaries have been published [10].

It is to be mentioned that, information was not abundant during Soviet Union period and the nationalization of terms entering our language and preparation works of dictionaries was relatively easier.

During the period of independence, as a result of the rapid development of Internet on one hand and integration of our country to global world as an open society on the other hand, the terminology activity has encountered major challenges against the multi-language information flow into national language environment. In other words, considerable threats have been posed to terminology security of our language.

Alongside with the achievements in terminology sphere, several problems are present in our country. Such that:

- Terminology activity in our country is not established in accordance with the requirements of international standards and recommendations, as well as the requirements of modern information-communication technologies, instead, carried out based on a longstanding tradition;

- Efficient mechanisms must be developed in order to engage volunteering and skillful citizens in terminology activity alongside with scientists and experts against the rapidly growing information flow;

- A unified registry of terminology dictionaries and other important materials is not present;

- Online terminology services are not provided to citizens;

- Despite the establishment of multiple electronic registries within the framework of e-government in our country, the formation of public and accessible terminology registry is a topical issue;

- There exists a necessity to utilize online social media technologies in order to improve the quality of terminological expertise work;

- The nationalization of international standards in terminology sphere is necessary;

- There emerges a necessity to conduct required works oriented to the integration of country's terminology system into international and foreign countries' online systems, as well as other national online systems;

- As the harmonization requirements are not followed during the process of term generation, terms in our 
language are used in various forms in different knowledge fields;

- It is necessary to carry out terminological monitoring and security works on books and online resources being used in our country;

- The conduction of specific measures for prohibiting the use of unapproved terminology dictionaries is necessary;

- It is important to duly approach the expertise works of terminology dictionaries; subjective opinion-based decision-making is unacceptable;

- There exists a need for protecting copyrights of scientists and experts (terminologists) developing terminology dictionaries;

- Seminars and trainings must be organized in order to discuss corresponding standards and recommendations, as well as progressive knowledge in terminology sphere;

- Scientific-research works oriented to the formation of e-terminology in terminology informatics and as a part of e-science require particular attention [11].

It is necessary to emphasize the principles and directions of the development of national terminology related to the systematization and coordination works in terminology sphere by analyzing achievements and existing limitations in national terminology.

The existing situation necessitates the reconstruction of terminological activity in our country by considering international practice and capabilities of modern technologies.

\section{International Practice and Standards in Terminology Sphere}

Terminology science as a scientific field has emerged in 30's of 20th century in the world. The establishment of terminology science is linked to the Austrian scientist Eugen Wüster. His early writings on terminology was published in 30's of past century and the first Terminology Center has been established under his leadership [12]. Terminology Center has implemented the projects of UNESCO and other international organizations and many scientists have been engaged in this work from different countries. The secretary of International Standardization Organization was founded under the guidance of E. Wüster in 1951.

International Information Centre for Terminology - Infoterm was founded in 1971 for the purpose of connection and support of cooperation in terminology field in the world [13]. Starting from 1977, Infoterm holds symposiums on various issues of terminology and implements important projects and programs. Infoterm promotes the idea of the establishment of new terminology centers and networks for the purpose of knowledge transfer in multilingual global world and implementation of information provision.

Infoterm was engaged in "Terminology development in network" project with the initiative of UNESCO in 1976 and as a result, TermNet (International Network for Terminology) has been organized [14].

At present, various international organizations are engaged in addressing the terminology problems throughout the world:

- EAFT - European Association for Terminology [15];

- IITR - International Institute for Terminology [16];

- IATE - Interactive Terminology for Europe - the multilingual term base of the EU [17].

It is to be noted that, terminology policy has been developed by multiple countries and the institutions regularly engaged in this work are established.

There exists a need for the regulation and standardization of works conducted in terminology field at international and national level.

For this purpose, Technical Committee (ISO/TC 37) which is a special institution regularly engaged in terminology works has been established by International Standardization Organization (ISO) and 5 subcommittees and 9 working groups have been organized under its leadership [18]. Approximately 50 
international standards have been adopted by ISO in terminology field. There emerged a necessity to recognize international standards adopted in terminology field as national standards.

New requirements will be posed to the recognition and adoption of standards, the design of National Terminology Information System (NTIS), its future use and development. On the other hand, the integration of NTIS with foreign countries, as well as corresponding international institutions will be facilitated.

At present, appropriate measures are being carried out in this direction by the State Committee of Standardization, Metrology and Patent of the Republic of Azerbaijan [19].

It is to be mentioned that, committees engaged in terminology work are present in more than 60 countries throughout the world.

Hence, much attention is devoted to the terminology activity in theoretical and practical terms over the world. It is because the success of scientific, technical and economic activity significantly hinges on accurately developed terminology.

\section{Research Works and Innovative Initiatives in Computational Terminology Field}

The field of computational terminology is shaped as an integral part of computational linguistics as a result ICT implementation in terminology field.

Research works in computational terminology in Azerbaijan were initiated in 2008 and numerous conceptual approaches and methods have been proposed. Some of those conceptual approaches are presented below:

\subsection{Automation of Term Generation Process}

1) Traditionally, terms are selected from texts and systemized by scientists and experts (terminologists) and published as books thereafter. Information flow via Internet has substantially perplexed this work. On the other hand, term generation process has become easier compared to past periods. Such that, while generating a term, every scientist and expert refers to Terminological Registry of NTIS in order to find out whether this term has been used previously. If so, there is no need for generating a term in that case. If this term does not exist in Terminological registry, this term is searched in NTIS of other countries integrated via NTIS, analyzed and effective decision is adopted. In other words, the process of international harmonization is carried out. In addition, Internet enables the acquisition of additional information (etymology, images, comments, etc.) regarding a new term.

2) Modern technologies enable the presentation of new terms not only as texts, but also via other forms of multimedia (image, audio, and video).

3) The access of people to information and their broadcasting via social media facilitates the rapid popularization of knowledge. Hence, terms applied in relatively narrow circles are rapidly determined. It is possible to analyze and evaluate the process of determination by automatically identifying the use frequency of term in public sphere. It is to be mentioned that, the indicators of termination and determination of notions hinge upon the area of spread of language, in other words, the size of country population.

\subsection{Formation of Citizen Terminology}

1) As the access of citizens to existing information resources and knowledge sources have become unbounded in virtual space as a result of rapid development of Internet technologies, the conduction of the process of term generation by scientists and experts causes the emergence of substantial problems. The solution of this problem envisions the participation of everyone willing to volunteer in public discussion and evaluation of terms. Active and massive participation of people in term generation works can facilitate the formation of CITIZEN TERMINOLOGY in our country. In this case, it is not necessary to collect and structure terms in book format, organize the evaluation and publication of those. Terms can be 
presented for public discussion regardless the number of those via modern technologies, including NTIS, and consensus can be reached with the application of various decision-making technologies in online regime.

2) Wikipedia technologies (WIKI-TERMINOLOGY) can be employed during the discussion of terms on online platforms and during the process of conversion of individual decisions to collective decisions.

3) In order to encourage the participation of citizens, their copyrights can be protected by issuing individual identification numbers (PIN-code) and certificates on adopted terms.

\subsection{Automatic Extraction of Terms from Texts}

1) Recently, key words and short contents (abstracts) are extracted and classified by applying data mining technologies.

2) These technologies have recently started to be applied for the determination of terms and main concepts in texts (Automatic Term Extraction) as well.

3) Currently, software tools are being developed and applied in practice for this purpose in developed countries.

4) Other noteworthy problems (ontology, online language resources, etc.) must be addressed alongside with terminological activity in order to facilitate the application of these technologies in Azerbaijani language.

\subsection{Analytical Terminology Problems}

1) Valuable information (Analytical Terminology) can be obtained by analyzing the parameters characterizing glossaries and terms collected in NTIS Terminological Registry, the rating of their use and etc. indicators.

2) Some judgement can be made based on EVOLUTION DYNAMICS (progress, deterioration) of a particular knowledge field according to the number of new terms adopted in specific periods.

3) Evaluations can be made regarding the integration and differentiation of, as well as semantic links among knowledge fields by analyzing the intersection of terms collections in pairwise and three-wise order pertaining to various knowledge fields and their evolution dynamics.

4) The level and rate of POPULARIZATION of a particular field can be determined according to the frequency dynamics (determination) of the use of terms in that field.

5) By comparing newly added books, monographs, dissertations and etc. materials with glossaries stored in Terminological registry, it can be determined to which fields or subjects at the intersection of fields these materials belong to (CLASSIFICATION).

6) The life cycle of terms (from termination to determination), trajectory and migration of knowledge fields can be critically evaluated by entering necessary information about terms (source country, knowledge field, etc.) to Terminological registry.

7) TERMINOLOGY NETWORK can be established based on the information regarding terms, semantic relations among terminological dictionaries and knowledge fields these terms belong to. As a result, the relevance of Internet search, machine translation, interpretation of notions and terms, etc. will be significantly facilitated [20].

\subsection{Problems of Provision of Terminology Security}

1) Incessant online monitoring of terminology can be carried out in order to detect unknown terms and concepts in materials contained in online resources.

2) The inspection of separate books to be published can be provided by comparing the electronic version of those with terms stored in Terminological registry.

3) As a result of the terminological monitoring conducted, ratings can be prepared reflecting various aspects. 
4) By analyzing necessary information (location, time, knowledge field, etc.) characterizing the terms adopted in our language, it is attainable to reveal tendencies, threats and etc. occurring in national terminology environment and adopt corresponding decisions.

5) Regular monitoring of terms must be carried out in order to avoid later alterations in the content of approved terminology glossaries.

6) The process of identification of terminology glossaries in use is facilitated which have not passed through appropriate inspection procedures.

\subsection{Educative-entertaining terminology}

Based on terminology glossaries stored in NTIS, various electronic terminology tests, crossword puzzles and computer games can be developed according to the level of advancement (all levels of classification).

Some of aforementioned conceptual approaches and techniques are considered during the establishment of NTIS.

\section{Conceptual Foundations of National Terminology Information System}

The globalization process in the world is characterized with the fact that, none of the languages has a closed terminology system, that is, interlanguage exchange of terms and definitions is present and this process is being accelerated. At present, widely used languages pose a problem of assimilation to narrowly used languages.

Primary approach of the generation of terminology must rest on a principle that, it is unacceptable to circumscribe the language environment (space) and thus, isolate the world from information and knowledge system. At the same time, leaving the language environment without boundaries and hence, exposing it to assimilation by advanced languages is inadmissible [21].

NTIS is a dynamically evolving open national information resource utilized in Internet environment.

The requirements of international standards, as well as e-government technology have been considered during the establishment of NTIS, and e-terminology services will be provided to users.

NTIS (E-TERMINOLOGY) is an integral part of E-SCIENCE which is one of the segments of EAZERBAIJAN being formed in our country (Fig.1).

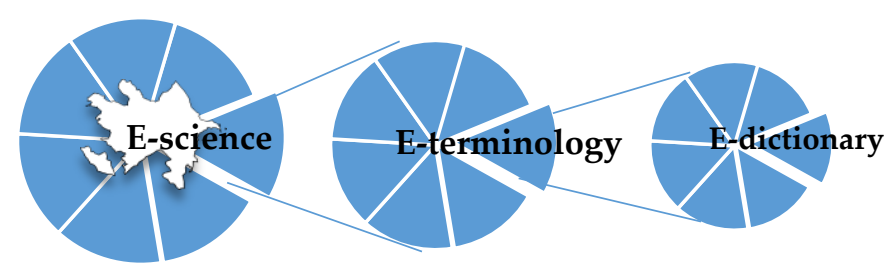

Fig.1. NTIS Location in Virtual Space

The core of NTIS will be constituted of TERMINOLOGICAL REGISTRY providing a secure storage of all terminology dictionaries in a unified online environment and available for everyone.

NTIS will possess the capability to integrate to international and foreign countries' analogical terminology systems.

At the same time, NTIS will play a role of an information database of scientific research works in the field of terminology informatics and will be upgraded with the application of modern technologies. 
One of the features of NTIS will facilitate the participation of volunteers alongside with scientists and experts in the process of the nationalization of terms flowing via Internet, in other words, the formation of Citizen Terminology will be supported.

\section{Architecture-Technological Principles of National Terminology Information System}

NTIS is a socio-technological system. Architecture-technological principles of NTIS have been developed in order to implement the tasks envisioned in the concept of the establishment of this system (Fig.2.).

NTIS is constituted of following functional subsystems:

- TERMINOLOGICAL REGISTRY

- INFORMATION PROVISION

- TERMINOLOGICAL EXPERTISE

- TERMINOLOGISTS

- SOCIAL MEDIA

- INTEGRATION

- ANALYTICAL TERMINOLOGY

- SCIENTIFIC RESEARCH

- ADMINISTRATORS

- SYSTEM MANAGEMENT

TERMINOLOGICAL REGISTRY is constituted of Terminological Glossary Fund (TGF), Terminology Database (TDB) and Data Backup System (DBS):

- All terminology dictionaries and other documents (books) are systemized and securely stored in TGF.

- Electronic version of terminology dictionaries is stored in TDB and user requests are responded.

- Reserve copies of electronic resources are stored in DBS.

Terminology glossaries published in different years and also existing in carriers are collected, digitalized and entered to TERMINOLOGICAL REGISTRY via INFORMATION PROVISION.

Based on information collected in TERMINOLOGICAL REGISTRY, E-terminology services are provided to users and other online functions are performed via TERMINOLOGY WEB-PORTAL.

Public discussion of dictionaries and other proposals by TERMOGPRAHERS will be carried out in both traditional and online environments within the framework of TERMINOLOGICAL EXPERTISE subsystem.

Dictionaries generated by scientists and experts (professional terminologists), as well as citizens (amateur terminologists) volunteering in generation of terms will be accepted in soft copy and via online environment, presented to terminological expertise and relations regarding the work progress are established via TERMINOLOGISTS.

SOCIAL MEDIA database provides the establishment of effective relations with publicity, the involvement of citizens to terminology generation works and the facilitation of their activity, as well as online discussion of terms and other related issues.

INTEGRATION subsystem provides the interoperability (transliteration, conversion, implementation of standard requirements, etc.) with appropriate terminology information systems of both within-country online environments and international and foreign countries' systems.

ANALYTICAL TERMINOLOGY subsystem will perform the functions of multipurpose monitoring, analysis and evaluation based on information collected in TERMINOLOGY REGISTRY and WEB-PORTAL.

ADMINISTRATORS will perform administrative functions on network, security, information system and technical service of NTIS.

SYSTEM MANAGEMENT will be performed by managers experienced in the field of establishment, exploitation and development of socio-technological systems. 
Both internal and external information exchange will be carried out by considering the requirements of edocument flow and e-signature technology in NTIS.

Within the framework of SCIENTIFIC RESEARCH subsystem, research is conducted in terminology informatics and other related fields, proposals and recommendations are developed oriented to the system intellectualization and improvement of efficiency indicators, expansion of functional capabilities and the application of innovative technologies.

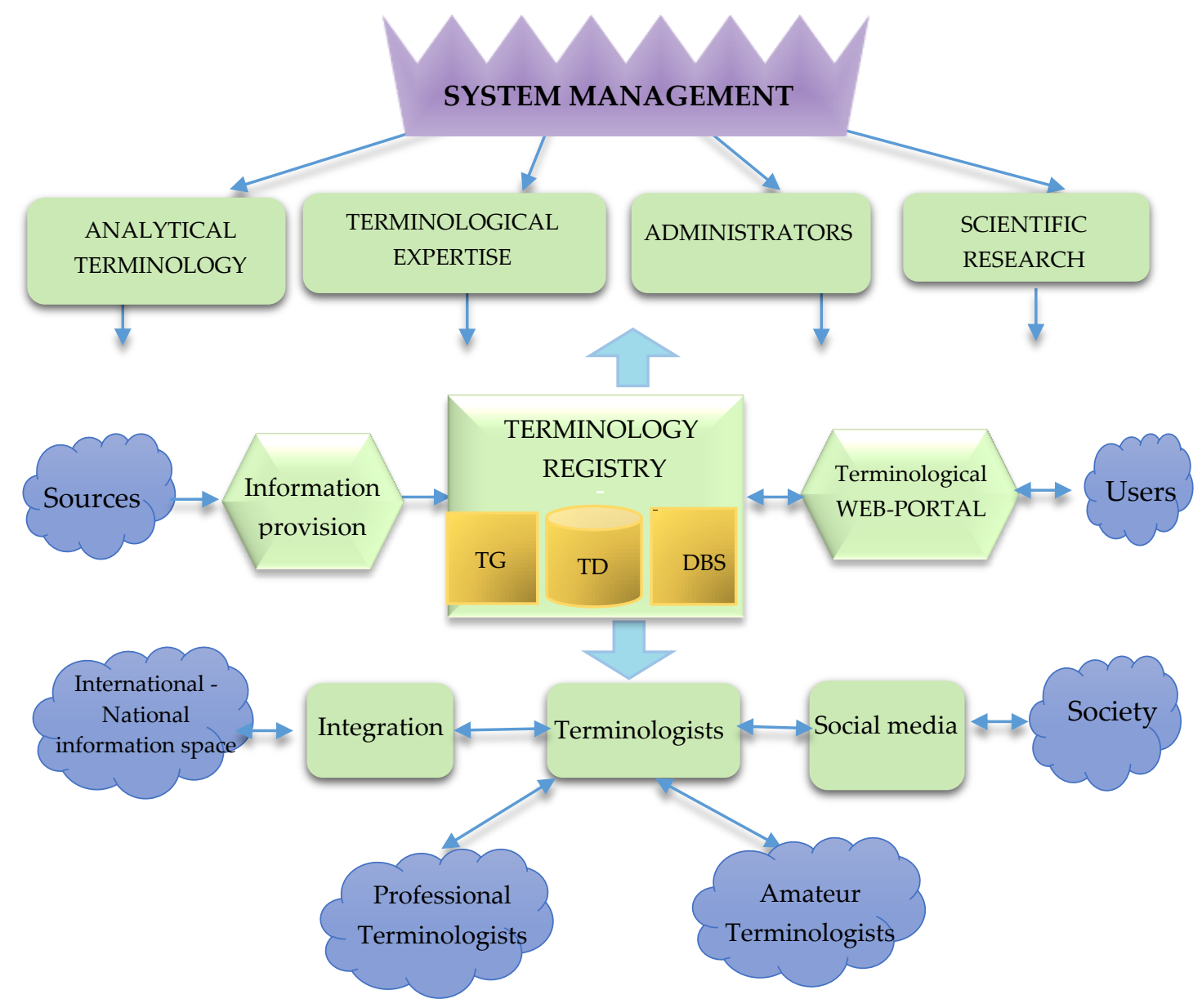

Fig.2. Structure of National Terminology Information System

\section{Web-Portal of National Terminology Information System}

NTIS web-portal has been established for the purpose of provision of the accessibility for each user after all existing terminology dictionaries are added in terminology information database [22].

When creating a Web site, it is important to properly select its software and set its modules [23]. These requirements are taken into account when creating the NTIS web portal.

The information foundation of NTIS web-portal is constituted of term database in all knowledge spheres, as well as network resources in this direction. This enables the system to be easily constructible and expandable as new terms and new segments of information resources can be integrated into it. 
NTIS web-portal represents a specialized information system; users are provided with web-interface.

From user's point of view, web-portal is a thematic Internet resource and provides information search and browsing capabilities of all fields of science and technology within the framework of terms. Primary functions of web-portal are illustrated in (Fig.3).

Web-portal as an Information resource:

- Provides the information accessibility in various aspects and presents information on multipurpose dictionaries (terminology dictionaries, other dictionaries (orthography, orthoepy, etc.)), on research works conducted in terminology field and researchers;

- Enables the integration into resources corresponding to this field presented in Internet;

- Presents search tools which are interesting for information user within whole information space of webportal;

- Enables the information support of web-resource user;

Supports a flexible user interface enabling the consideration of user opinions on web-resource and presented services.

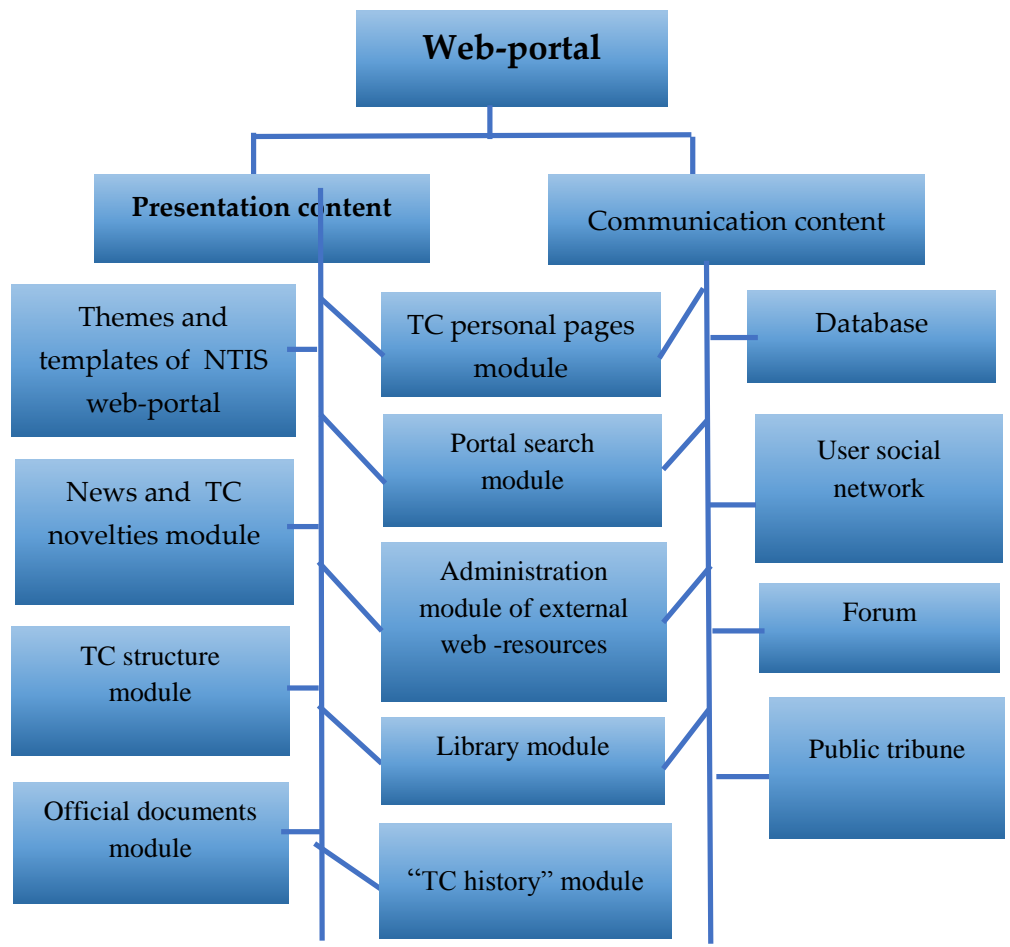

Fig.3. Main Functions of Web-portal

\section{Conclusions}

The works conducted regarding the establishment of NTIS reveal its future perspectives. The implementation of NTIS will lead to the achievement of following capabilities:

- Citizens and any user regardless the geographical local will be provided with e-terminology services; 
- Voluntary engagement of people in term generation process, presentation of complaints and proposals and their participation in online forums devoted to the discussion of prepared terminology dictionaries will boost the formation of citizen terminology;

- The efficiency of term generation will increase as a result of the collection of terminology dictionaries prepared in various spheres in a unified information system (presence of terms, harmonization, etc.);

- Wide opportunities will be presented as a result of transparency and easy accessibility for protecting copyrights of scientists and experts participating in the development of terminology glossaries;

- The processing of feedback information on terminology glossaries and separate terms will enable to conduct analysis and evaluation of various content and organize ratings;

- The integration of national terminology system with analogical systems of international arena and foreign countries will be accelerated;

- The formation and development of terminology database in Azerbaijani language will be facilitated at great extent;

- They will act as an information database for research conducted in terminology sphere;

- The conduction of terminology activity based on international and national standards will be supported.

\section{References}

[1] Drezen E.K. In the pursuit of universal language. Three centuries of research. 3rd edition - M: "Editorial URSS", 2012, 272 p.

[2] Wüster Eugen. The machine tool: an interlingual dictionary of basic concepts, Technical Press, 1967, $159 \mathrm{p}$.

[3] Volodina M.N. Terms as a cognitive-information models necessary in the process of professionalscientific communication. Journal of Scientific-technical terminology, Vol. 1, 2011.

[4] Gryaznuxina T.A. et al. Application of ECM in linguistics research. Kiev, 1990.

[5] Kageura K. The Dynamics of Terminology, Terminology and Lexicography Research and Practice, 5, John Benjamins Publishing, 2002, 322 p.

[6] Khurshid Ahmad, Affective Computing and Sentiment Analysis: Metaphor, Ontology and Terminology, Heidleberg, Springer Verlag, 2011, 1-162 pp.

[7] Meyer I., Skuce D., Bowker L., Eck K. Towards a New Generation of Terminological Resources: An Experiment in Building a Terminological Knowledge Base, COLING-92, NANTEs. AUG. 23-28, 1992, 956-960, http://acl.ldc.upenn.edu/C/C92/C92-3146.pdf

[8] Boguraev B., Levin B. Models for Lexical Knowledge Bases, in J. Pustejovsky, ed., Semantics and the Lexicon, Kluwer, Dordrecht, also appears in Electronic Text Research, Proceedings of the Sixth Annual Conference of the Centre for the New OED, University of Waterloo, Waterloo, Ontario, 1990, 65-78 pp.

[9] Sadigova S. History of emergence and development of terminology in Azerbaijani language, Baku, "Elm", 2005, 348 p.

[10] Sadigova S. The terminology of Azerbaijani language. Baku, "Elm", 2011, 380 p.

[11] Gurbanova A.M. Scientific-technological research conducted in computational terminology and their comparative analysis. Problems of Information society, Baku, 2013, №2(8), 3-12.

[12] Wüster Eugen. Internationale Sprachnormung in der Technik, besonders in der Elektronik. Berlin, 1931. $431 \mathrm{p}$.

[13] International Information Centre for Terminology. www.infoterm.info

[14] International Network for Terminology. www.termnet.org

[15] European Association for Terminology. www.eaft-aet.net

[16] International Institute for Terminology Research. http://iitf.fi/cms/

[17] Interactive Terminology for Europe. http://iate.europa.eu/

[18] International Organization for Standardization. www.iso.org 
[19] The State Committee for Standardization, Metrology and Patent of the Republic of Azerbaijan. http://www.azstand.gov.az/

[20] Gurbanova A.M., Automated construction of the semantic network of subject field terms technologies. Problems of information technology, Baku, 2018, №1, 75-82

[21] Alguliyev R.M., Gurbanova A.M. Terminology information system and development perspectives. Terminologiya meseleleri, Baku, 2010, 27-33.

[22] www.terminologiya.az

[23] Feng Bing. Website Design and Maintenance of University PE Excellent Courses Based on Web Technique. International Journal of Education and Management Engineering, 2012, 5, 43-47.

\section{Authors' Profiles}

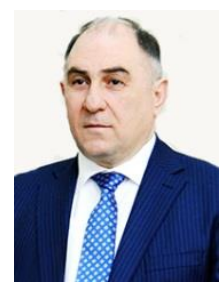

Rasim M. Alguliyev. He is director of the Institute of Information Technology of Azerbaijan National Academy of Sciences (ANAS) and academician-secretary of ANAS.

$\mathrm{He}$ is full member of ANAS and full professor. He received BSc and MSc in electronic computing machines from the Azerbaijan Technical University in 1979. He received his $\mathrm{PhD}$ and Doctor of Science (higher degree after PhD) in Computer Science in 1995 and 2003, respectively. His research interests include: Information Security, E-government, Data Mining, Big Data, Online Social Network Analysis, Cloud Computing, Evolutionary and Swarm Computation, and Scientometrics. He is author more than 552 papers, 4 monographs, 4 patents, several books.

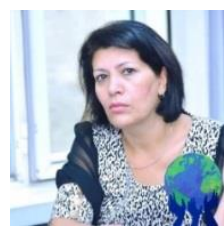

Afruz M. Gurbanova. Afruz M. Gurbanova graduated from Applied Mathematics faculty of Azerbaijan State University (ASU).

After graduating from ASU worked at the Institute of Cybernetics of Azerbaijan Academy of Sciences as a developer. Her area of interest includes web technologies, computational linguistics, computational terminology, Data Mining technologies, particularly e-Azerbaijan state program and the development of the information system for the national terminology within the framework of the State Program related to the use of Azerbaijani language in accordance with the requirements of the globalized world and the development of linguists in the country within.

How to cite this paper: Rasim M. Alguliyev, Afruz M. Gurbanova,"The Conceptual Foundations of National Terminological Information System", International Journal of Education and Management Engineering(IJEME), Vol.8, No.4, pp.19-30, 2018.DOI: 10.5815/ijeme.2018.04.03 